\title{
Potential Carbon Footprint Reduction for Reclaimed Asphalt Pavement Innovations: LCA Methodology, Best Available Technology, and Near-Future Reduction Potential
}

\author{
Diana Eliza Godoi Bizarro ${ }^{1, *}$, Zoran Steinmann ${ }^{2}$, Isabel Nieuwenhuijse ${ }^{3}$, Elisabeth Keijzer ${ }^{1}$ and Mara Hauck ${ }^{1}$ \\ 1 Climate Air and Sustainability Department, The Netherlands Organisation for Applied Scientific Research, \\ 3584 CB Utrecht, The Netherlands; elisabeth.keijzer@tno.nl (E.K.); mara.hauck@tno.nl (M.H.) \\ 2 Environmental Systems Analysis Group, Wageningen University, 6708 PB Wageningen, The Netherlands; \\ zoran.steinmann@wur.nl \\ 3 Energy Sector, CE Delft, 2611 HH Delft, The Netherlands; Nieuwenhuijse@ce.nl \\ * Correspondence: diana.godoibizarro@tno.nl; Tel.: +(31)-6-1517-6932
}

check for updates

Citation: Bizarro, D.E.G.; Steinmann Z.; Nieuwenhuijse, I.; Keijzer, E.; Hauck, M. Potential Carbon Footprint Reduction for Reclaimed Asphalt Pavement Innovations: LCA Methodology, Best Available Technology, and Near-Future Reduction Potential. Sustainability 2021, 13, 1382. https://doi.org/ $10.3390 /$ su13031382

Academic Editor: Rui Micaelo

Received: 23 December 2020

Accepted: 22 January 2021

Published: 28 January 2021

Publisher's Note: MDPI stays neutral with regard to jurisdictional claims in published maps and institutional affiliations.

Copyright: (c) 2021 by the authors. Licensee MDPI, Basel, Switzerland. This article is an open access article distributed under the terms and conditions of the Creative Commons Attribution (CC BY) license (https:/ / creativecommons.org/licenses/by/ $4.0 /)$.

\begin{abstract}
The carbon footprints of asphalt mixtures with increasing reclaimed asphalt pavement (RAP) content were estimated using a life-cycle assessment methodology. Three asphalt mixtures with different applications and technical requirements, namely porous asphalt (PA), stone mastic asphalt (SMA), and asphalt concrete (AC), were included. The technology leaps needed to achieve asphalt mixtures containing up to $93 \%$ RAP were modelled. Mixtures containing up to $57 \%$ RAP were hot-mix asphalts $\left(175^{\circ} \mathrm{C}\right)$, while mixtures containing more RAP were produced at $135^{\circ} \mathrm{C}$ and $105^{\circ} \mathrm{C}$. The energy requirements and their respective carbon footprints were calculated based on the heat capacity of the aggregates, RAP, and other bituminous materials. Furthermore, the effects of changing the country's electricity mix were also evaluated. A potential carbon footprint reduction of between $55 \%$ and $64 \%$ was found for one tonne of asphalt containing $93 \%$ RAP and produced at $105{ }^{\circ} \mathrm{C}$ compared to the $0 \%$ RAP mixture produced at $175^{\circ} \mathrm{C}$. Considering the uncertainty of this technology at its early stage of development, the reduction could be as low as $45 \%$ or as high as $79 \%$. Changing the electricity mix to one that is likely to be implemented until 2030 in the Netherlands further reduces the footprint by $10 \%$.
\end{abstract}

Keywords: circular asphalt; asphalt recycling; asphalt life-cycle assessment; WMA; RAP; asphalt innovation; TRL; carbon footprint reduction

\section{Introduction}

With the signing of the Paris Agreement in 2015, almost all countries have pledged to reduce their greenhouse gas (GHG) emissions drastically. Emission reduction targets have been implemented or proposed for many different sectors, including the road construction sector. The road construction sector is responsible for more than 5\% of GHG emissions generated in Europe [1]. Choosing asphalt mixtures with lower carbon footprints can contribute to reaching a country's climate change reduction targets [2]. Rijkswaterstaat (RWS), the Dutch road authority, established a goal of GHG emission reduction by 30\% by 2020 in comparison to 2009, and it aims to be a carbon-neutral organisation in 2030 [3].

About $90 \%$ of the carbon footprint of asphalt roads in the Netherlands is concentrated in the production of raw materials-more specifically, bitumen and crushed stonetransporting the materials to the asphalt plants, and producing the asphalt mixture [4]. This means that a significant amount of the annual GHG emissions can be avoided using materials with smaller carbon footprints, such as secondary or bio-based materials, by consuming less energy during production by mixing asphalt at lower temperatures, using less carbon-intensive equipment, machinery, and transportation, or by elongating the service life of the asphalt $[5,6]$. Feedstock- and construction-related GHG reduction 
measures include the use of recycled asphalt, industrial waste, or by-products as alternative materials, as well as changed construction, such as with two-lift pavements, rejuvenating measures, and adapted rehabilitation, such as cold in situ recycling $[7,8]$. Elongation of service life could be achieved by adding polymers or fibres to the asphalt mixtures [6]. In asphalt pavement life-cycle assessment (LCA) studies, Refs. [9,10] summarised secondary materials with the potential to reduce carbon footprints: recycled pavement materials, rubber, polymers, fly ash, and other waste products.

These are new technologies in different stages of development. Making a first estimate of the potential environmental benefits of such new asphalt technologies at an early stage of development can help support investment decisions and strategic decision making to reduce the asphalt-related GHG emissions. The maturity of a technology, including asphalt technologies, can be expressed in terms of its technology readiness level (TRL), which is attributed to a technology according to the development steps it has already gone through. In general, the lower the technological readiness level, the more difficult it is to calculate the potential environmental impact of the technology at its full maturity level due to the lack of data. For example, there are a multitude of studies that quantify the environmental benefits of warm-mix asphalt (WMA) technologies, which reduce the temperature by 20-30 degrees Celsius compared to hot-mix asphalt (HMA), and on the use of reclaimed asphalt pavement (RAP) in the base or binding layers $[8,11-14]$, as well as a few on wearing or friction courses $[13,15]$. However, in none of the studies has RAP content exceeded $50 \%$, which means that only technologies with high TRLs have been investigated so far. As more challenging concepts at lower TRLs are proposed, such as $>90 \%$ RAP combined with WMA, the technological information is usually limited to technical details [16], and information about the potential environmental performance is not readily available. The only exception that we are aware of is the study by [17], who investigated asphalt concrete mixtures for different asphalt layers with increasing RAP contents from $0 \%$ to $100 \%$, and concluded that increasing RAP contents lead to a linear decrease in environmental impacts.

At the same time, adding environmental information in an early development stage is of particular relevance because results can be taken into account by technology developers [18]. Several papers have been published that describe approaches to estimating the environmental impact of emerging photovoltaic cells, chemicals, and aerogels [19-21]. Many of these studies focus on developments from the lab/pilot to the industrial scale. Research into innovations in the asphalt industry, however, are often performed in asphaltproducing plants. Moreover, the same production technology will not be market available for all asphalt types in the same time path due to the different performance and safety requirements for different functions. For instance, Ref. [6] performed an analysis of only base layers because the use of RAP is not allowed in surface layers in Flanders. Moreover, many studies have assessed the specific RAP contents for a specific combination of layers in a project $[12,22-24]$ and, based on that, made extrapolations to other layers produced with new asphalt technologies. Therefore, the estimation of the potential carbon footprint reduction of a new asphalt production technology requires an approach that systematically considers the differences in TRLs, asphalt types, and specific applications for innovative asphalt mixtures. To the best of our knowledge, such an approach has not yet been presented.

The aim of this paper is to propose and apply such an approach for the example of asphalt with varying degrees of RAP that exceed the ones previously addressed in peer-reviewed LCAs. To account for the differences in application and performance requirements, three asphalt types commonly used in the Netherlands are included: two wearing-course mixtures (one for high traffic and one for low to medium traffic) and one binder-/base-layer mixture. The proposed method and case study follow a number of steps. First, the currently used mixtures are defined; then, the technological solutions for further increasing RAP contents are investigated and their TRLs are defined. Information on these technological solutions is then used to estimate the deviations from the state-of-the-art technologies. As it will take time before these technologies are on the market, a future 
situation was taken into account, which reflects changes in the general economy as well as in the industry (e.g., changes in energy supply, [25]). These technological and exogenous changes are combined to present new carbon footprints for the three mixtures in the years 2020 and 2030.

\section{Materials and Methods}

\subsection{Scope and System Boundaries}

In this study, the effects on the carbon footprints of three asphalt mixtures by progressively increasing the recycled material content were investigated. The technological requirements for doing so and their current TRLs are also included. The carbon footprint is defined as the life-cycle sum of emissions of gases that have the potential to contribute to the global warming phenomenon, as defined by the Intergovernmental Panel for Climate Change [26], and it is expressed as the emissions of $\mathrm{CO}_{2}$ equivalents in mass.

The case study is a cradle-to-gate analysis, and the functional unit is defined as "one tonne of a bituminous asphalt mixture at a batch asphalt plant in the Netherlands in 2020 and 2030". Road construction, use phase, and end of life are excluded from the analysis because the RAP-containing asphalt mixtures are considered to be of equal quality in terms of workability and lifetime compared to their conventional counterparts, making these latter stages identical. Therefore, the included phases are: the extraction and processing of the materials in the asphalt mixtures, road transport of these materials to the asphalt plant, and the production of the asphalt mixture in the asphalt plant.

The included mixtures are widely used in the Netherlands-namely, porous asphalt (PA), stone mastic asphalt (SMA), and asphalt concrete for the binder and base layers (AC bin/base). PA is an asphalt mix that is largely used for the wearing courses of highways with heavy traffic in the Netherlands. It has high performance requirements in terms of safety, service life, drainage, and noise reduction. It is a hot-mix asphalt that requires good-quality, uniformly graded aggregates. SMA is also applied to wearing courses, but in provincial and local roads with low and medium traffic intensities; as opposed to PA, it has a closed grained structure. In terms of performance requirements, SMA needs to be safe and to deliver a comparatively long service life with low maintenance needs. AC bin/base is a dense-graded HMA with a larger nominal maximum aggregate size, and is intended for instance for use as a base course or binder course for PA wearing courses. The main requirement for this layer is to provide support to the wearing courses above it.

\subsection{Technology Readiness Level}

To assess innovations, it is useful to estimate the development stage of a technology. This estimate gives an idea of how much research is still needed and how much improvement can still be expected. Generally, the TRL is used for this. Developed by NASA, the indicator has been widely used in the US defence industry and is also increasingly used in other engineering fields. In Europe, the European Space Agency (ESA) and the European Commission use the TRL concept and have definitions for each level, which are shown in Table 1.

Technologies between TRLs 1 and 4 are technologies in the design phase, from conceptual ideas to testing in a lab setup. From TRL 5, the first practical tests in situ under real conditions are done. For asphalt, it is in this stage that the first testing lanes are laid and their behaviour is observed under real conditions. From TRL 5 until TRL 8, the traffic intensity for testing the asphalt layers increases progressively. At TRL 9, the asphalt mixture can be applied to the regular road network and evaluated regularly until validation. After validation, the production process can be scaled up [27].

Innovations are applied differently according to the asphalt's type and use. Differences in applicability are also related to the differences in test standards and safety requirements for different roads and traffic intensities. New technologies are usually allowed to be applied in foundation layers first, then in base and binder layers, and then in roads with low traffic intensity, such as provincial roads, which are usually paved with SMA or surface 
asphalt concrete mixtures. After testing in smaller roads with low traffic, the final step is to lay the innovative asphalt mixture in highways with high traffic intensity, where PA is usually used. Therefore, for mixtures using the same production technology, the trajectory to application can still vary and will be longer from foundation layers to major PA roads.

If a technology has not yet been commercially applied on a large scale, then both the costs and the environmental impact (e.g., raw materials used, energy) with full upscaling for all applications are not yet certain. To map the uncertainties per asphalt mix in the best possible and comparable way, we assigned a degree of uncertainty to the levels of development of the technologies (TRLs) and to their applications in specific layers using expert judgement. We thereby assumed that uncertainty increases with application in layers with stricter performance requirements. The TRL descriptions and resulting uncertainty estimates per layer are described in Table 1.

Table 1. Description of the technology readiness levels (TRLs) with estimates for the uncertainties. The TRL numbering and description are based on [28], and the environmental impact uncertainty is based on expert judgement.

\begin{tabular}{|c|c|c|c|c|c|}
\hline TRL & Description & Technology & Base Layer & SMA & PA \\
\hline 1 & Basic principles observed & $>50 \%$ & $>50 \%$ & $>50 \%$ & $>50 \%$ \\
\hline 2 & Technological concept formulated & $>50 \%$ & $>50 \%$ & $>50 \%$ & $>50 \%$ \\
\hline 3 & Technological concept proven & $>50 \%$ & $>50 \%$ & $>50 \%$ & $>50 \%$ \\
\hline 4 & Technology validated in a lab setting & $40 \%$ & $>50 \%$ & $>50 \%$ & $>50 \%$ \\
\hline 5 & Technology validated in a relevant environment & $30 \%$ & $40 \%$ & $>50 \%$ & $>50 \%$ \\
\hline 6 & Technology demonstrated in a relevant environment & $25 \%$ & $30 \%$ & $40 \%$ & $>50 \%$ \\
\hline 7 & Prototype system demonstrated in an operational environment & $20 \%$ & $25 \%$ & $30 \%$ & $40 \%$ \\
\hline 8 & System complete and qualified & $10 \%$ & $20 \%$ & $25 \%$ & $30 \%$ \\
\hline 9 & $\begin{array}{l}\text { Actual system proven in an operational environment } \\
\text { (competitive in the market) }=\text { foundation }\end{array}$ & $5 \%$ & $10 \%$ & $20 \%$ & $25 \%$ \\
\hline
\end{tabular}

\subsection{System Description}

The asphalt types and innovative technologies investigated in this study are described in the following subsections.

\subsubsection{Asphalt Production}

Hot-mix asphalt is the most common way of producing asphalt. It consists of heating primary materials, such as fillers (hydrated lime), aggregates (gravel, sand), and a bituminous binder, up to temperatures above $150-175^{\circ} \mathrm{C}$. Raising the temperature has the effect of reducing the viscosity of bitumen, which allows it to uniformly coat the aggregate material, firmly binding it together after cooling down. The heating requirement is usually met by burning fossil fuels-typically gasoil or natural gas. Asphalt plants can produce asphalt in batches or continuously using drums; both types use a similar set of equipment and technologies. They are equipped with conveyor belts, heating and drying drums, mixers, crushers, and cranes, as well as other equipment used to produce the asphalt up to the point when it is ready to lay.

\subsubsection{Reclaimed Asphalt Pavement}

Reclaimed asphalt pavement (RAP) is the secondary material obtained after the removal of an asphalt layer that may be used to substitute primary material in the subsequent asphalt life cycle. The standard procedure in the Netherlands is to include RAP in base layers with up to $50 \%$ in content of mass. The major challenges in increasing the recycled content in the asphalt base and surface layers are the higher humidity of RAP materials due to weather exposure, the increased stiffness of bitumen due to aging/weathering, and the increase in finer fractions of aggregate after RAP processing because each asphalt type 
requires different fractions of an aggregate grade, which vary according to mix design. These factors make it difficult to achieve the performance requirements for wearing courses of high-traffic highways that include RAP. Several widely used asphalt-producing technologies can also be used to increase RAP content: rejuvenators, parallel drums, and warm-mix asphalt. However, new technologies, like foamed bitumen, are required to further increase RAP content.

\section{Rejuvenators}

Rejuvenators lower the viscosity of bitumen, which improves the coating of aggregates and the workability of the asphalt mix; moreover, this has a rejuvenating effect on the aged bitumen. Consequently, rejuvenators make it possible to meet the quality standards demanded for surface layers when RAP is used. Adding rejuvenators and up to $30 \%$ RAP to surface layers is already common in the Netherlands; therefore, this technology is rated TRL 9. For base layers, like AC bin/base, rejuvenators are added from $50 \%$ RAP to ensure that a uniform asphalt mixture with well-coated and bonded aggregates can be produced without adding extra primary bitumen.

\section{Parallel Drum}

Currently, it is possible to reduce RAP humidity without causing further aging by using a parallel drum that heats the secondary materials separately from the primary materials at a maximum temperature of $120^{\circ} \mathrm{C}$. This means that the primary materials must be warmed up to a higher temperature to compensate the lower RAP temperature so that a final mixing temperature above $150^{\circ} \mathrm{C}$ can be reached when primary and secondary materials are mixed. The high temperature also ensures a good workability of the asphalt mixture at the construction site. The maximum temperature to which asphalt can be safely heated without igniting the bitumen content is between 230 and $250{ }^{\circ} \mathrm{C}$ [29-31]. Therefore, the maximum temperature used to overheat the primary materials was $250^{\circ} \mathrm{C}$, limiting the maximum RAP content in HMA to $58 \%$, even with the use of rejuvenators. This technology is already in use in the Netherlands, and the TRL is rated at 9. In the Netherlands, it is standard procedure to apply up to 50\% RAP in the base layers produced using parallel drums.

\section{Warm-Mix Asphalt}

If a mixture contains more than 57\% RAP in mass, it is no longer possible to overheat the primary materials to such an extent that a final temperature of $150-175{ }^{\circ} \mathrm{C}$ is reached when mixing all materials. Therefore, mixtures are produced under temperatures between 105 and $150^{\circ} \mathrm{C}$ - so-called warm mix asphalt (WMA). An additive is always necessary to improve the binder coverage of all aggregates and the workability of the asphalt mixture on site at these temperatures, independently of RAP content. Production of WMA and asphalt mixes including RAP is already in place. In 2017, almost $40 \%$ of the total tonnage in newly laid asphalt pavement in the USA was WMA [32]. However, WMA with RAP above 58\% is not currently applied to base or surface layers in the Netherlands because regulations limit the amount of RAP that can be applied to the layers, and the current technology does not allow the production of an asphalt mixture with a higher RAP percentage that meets all its requirements [33,34]. Therefore, we estimate the TRL of WMA with RAP percentages above $50 \%$ to be TRL 7, which is also in line with recent research from Rijkswaterstaat, the Dutch road authority [35].

The maximum RAP content that can be achieved with WMA mixtures is $70 \%$. Reducing the production temperature to lower than $150^{\circ} \mathrm{C}$ allows the incorporation of more RAP in the mix design while preventing further aging of the bitumen present in RAP. This can be achieved using foamed bitumen (water-based or water-containing) or organic or chemical-additive-based technologies [11]. 


\section{Foamed Bitumen/Low Temperature}

Higher recycled content and lower-temperature production can be achieved using the foamed bitumen technology, in which case asphalt can be produced at temperatures between 95 and $105{ }^{\circ} \mathrm{C}$ (comparable to half-warm mixtures). At such low temperatures, a good mixing can no longer be achieved just by adding rejuvenators; thus, bitumen foaming can be used to ensure that aggregates are well coated by the binder. Bitumen foaming mixes bitumen at high temperatures $\left(170^{\circ} \mathrm{C}\right)$ with water at room temperature, and both are injected into an expansion chamber through a nozzle. When both substances make contact, bubbles are formed, causing the bitumen to expand, which allows the binder and granulate to be better mixed. Workability and bitumen aging are not the only challenges to be solved when a higher amount of RAP is used. The increase in finer fractions of aggregate after processing RAP prevents an optimal mix design; thus, sieving RAP to sort secondary aggregates according to their grade is necessary to enable the production of high-quality secondary asphalt mixes.

Low Emission2 Asphalt Pavement (LE2AP) is an example of this production method for which data are available [36]. In order to produce high-RAP-content mixtures at relatively low temperatures, the asphalt granulate must go through a process similar to that of primary asphalt mixtures, which comprises sorting RAP by grade so that the secondary asphalt mixture has the same aggregate fractions as primary mixtures. Having the right amount of each aggregate fraction is important for achieving the desired amount and size of voids in the asphalt layer. Sieving RAP also allows the separation of a fraction of fine materials that is rich in bitumen, which gets mixed with primary bitumen. This mixture of secondary sand, secondary bitumen, and primary bitumen is heated to a temperature of $170{ }^{\circ} \mathrm{C}$ and foamed using water. An electric bitumen foaming machine must be used for this [16]. The primary and secondary aggregates are heated in parallel to a temperature of $105^{\circ} \mathrm{C}$ and mixed at the same temperature with the foamed bitumen. The first mixtures using this process were made around 2015 within the Life + EU project. Nowadays, tests are also being carried out on provincial roads in the Netherlands and Germany. Therefore, the TRL for this technology is around 5. An RAP content of 93\% is considered to be the maximum for surface layers because it is the highest amount reported so far.

\subsection{Life-Cycle Inventory Modelling}

\subsubsection{Material Composition}

Current State Technologies

The current state mixes used in this paper-AC bin/base, SMA, and PA-were modelled based on industry-average references from [4]. This author reported the compositions and environmental impacts of representative asphalt mixtures used in the Netherlands. The compositions of the three asphalt types investigated in this paper are shown in Table 2. Furthermore, the modelling followed the European standard EN 15804 and EN 17932-1, which prescribes the calculation rules for environmental product declarations of construction products. Life-cycle inventories for the production and transport to the market of the raw materials needed for producing asphalt were taken from Ecoinvent 3.5, except for bitumen and crushed rock (i.e., aggregates), which were taken from the Nationale Milieu Database (NMD v.3.1, December 2019). This process does not include transport from the refinery to the asphalt plant. Therefore, we assumed a transport distance of $100 \mathrm{~km}$ for bitumen by a large freight lorry. All Ecoinvent processes were modelled as processed from the market, and they therefore included standard transport distances and infrastructure. All other transport distances were modelled as in [4]. A list of the selected Ecoinvent market processes and their corresponding carbon footprints is provided in the Supplemental Material (Table S1). No additional transport was added for these processes. About $90 \%$ of the carbon footprint from road infrastructure in the Netherlands is concentrated in the production of raw materials (more specifically, bitumen and crushed stone), transporting the materials to the asphalt plants, and producing the asphalt mixture. The major sources of GHG emissions in production and transport are fuel and electricity consumption [4]. 


\section{Mixtures Including RAP}

Variants with RAP content from $0 \%$ to $93 \%$ were modelled for each mixture (AC $\mathrm{bin} /$ base, SMA, PA). To achieve this, the following adjustments were made compared to the reference mixtures:

- Where necessary, the mass percentage of bitumen was adjusted in relation to the reference mixture.

- RAP was assumed to be removed from old roads, broken, and mixed with dieselfuelled machinery. For re-use in surface layers (PA and SMA), RAP needs to be fully broken, leading to a higher energy consumption $(15.8 \mathrm{MJ} / \mathrm{t})$ than for binder and base layers $(7.38 \mathrm{MJ} / \mathrm{t})$.

- Diesel is also used by excavators and cranes at asphalt plants and was kept constant at $0.0059 \mathrm{MJ}$ per tonne of asphalt produced.

- The heat requirement for asphalt production were calculated based on the heat capacity of the materials in each asphalt mix and the initial and final temperatures. The initial temperature was considered to be $15^{\circ} \mathrm{C}$, while the final temperature varied between 175 and $105{ }^{\circ} \mathrm{C}$ with RAP content (see Section 2.4.2). Bitumen is heated and foamed with electricity, as opposed to all other materials, which are heated with natural gas.

- For surface-layer mixtures (SMA and PA) with up to 70\% RAP content, additives (rejuvenators) were included in the modelling as "chemical, organic" in line with [4]. Additives were added from $1 \%$ RAP content at a rate of $0.4 \%$ and $0.5 \%$ of total bitumen content to SMA and PA, respectively.

- For the surface-layer mixtures containing more than $70 \%$ RAP, the additive used by [16] was applied. It is an additive produced using tall oil from paper pulp production, which was added to the top-layer mixtures at a rate of $10 \%$ of aged bitumen content in RAP, as recommended by the producer [37].

- For AC bin/base, the tall-oil-based additive was added from an RAP content of 50\% at a rate of $0.75 \%$ of the total bitumen content in the mixture.

- Pavement to be reclaimed has to be transported from the road to the asphalt plant; this distance was assumed to be $50 \mathrm{~km}$. Both bitumen and RAP were assumed to be transported by a large freight lorry (freight lorry $>32 \mathrm{t}$, EURO 5 standards).

Table 2. Composition of one tonne of asphalt mixture for different shares of reclaimed asphalt pavement (RAP) content.

\begin{tabular}{|c|c|c|c|c|c|c|c|c|c|c|c|c|}
\hline \multirow{2}{*}{$\begin{array}{c}\text { Raw } \\
\text { Material }\end{array}$} & \multicolumn{4}{|c|}{ PA } & \multicolumn{4}{|c|}{ SMA } & \multicolumn{4}{|c|}{ AC bin/base } \\
\hline & $0 \% 1$ & $58 \%$ & $71 \%^{2}$ & $93 \%^{3}$ & $0 \%^{1}$ & $58 \%$ & $71 \%^{2}$ & $93 \%^{3}$ & $0 \% 1$ & $58 \%$ & $71 \%^{2}$ & $93 \%$ RAP $^{3}$ \\
\hline $\begin{array}{c}\text { Bitumen, } \\
\text { primary }(\mathrm{kg})\end{array}$ & 52.00 & 23.00 & 27.70 & 22.50 & 66.00 & 31.00 & 37.00 & 37.40 & 45.00 & 16.00 & 16.00 & 16.39 \\
\hline Filler (kg) & 51.00 & 51.00 & 6.40 & 0.00 & 14.00 & 14.00 & 18.70 & 0.00 & 10.00 & 10.00 & 8.30 & 4.97 \\
\hline$\underset{(\mathrm{kg})}{\text { Aggregates }}$ & 895.00 & 345.00 & 234.80 & 45.40 & 842.00 & 337.70 & 197.70 & 30.20 & 558.00 & 232.00 & 194.00 & 18.37 \\
\hline RAP (kg) & 0.00 & 580.00 & 711.00 & 931.00 & 0.00 & 580.00 & 710.00 & 931.00 & 0.00 & 580.00 & 721.00 & 925.00 \\
\hline Sand $(\mathrm{kg})$ & 0.00 & 0.00 & 19.40 & 0.00 & 75.00 & 30.10 & 26.50 & 0.00 & 387.00 & 161.00 & 53.00 & 32.81 \\
\hline Fibres (kg) & 2.00 & 0.80 & 0.00 & 0.00 & 3.00 & 1.20 & 0.00 & 0.00 & 0.00 & 0.00 & 0.00 & 0.00 \\
\hline Additive (kg) & 0.00 & 0.40 & 0.86 & 1.10 & 0.00 & 0.50 & 1.50 & 2.00 & 0.00 & 0.35 & 0.49 & 0.49 \\
\hline $\begin{array}{l}\text { Additive } \\
\text { type }\end{array}$ & & $\begin{array}{l}\text { Chemical, } \\
\text { organic }\end{array}$ & $\begin{array}{l}\text { Tall-oil } \\
\text { based }\end{array}$ & $\begin{array}{l}\text { Tall-oil } \\
\text { based }\end{array}$ & & $\begin{array}{l}\text { Chemical, } \\
\text { organic }\end{array}$ & $\begin{array}{l}\text { Tall-oil } \\
\text { based }\end{array}$ & $\begin{array}{l}\text { Tall-oil } \\
\text { based }\end{array}$ & & $\begin{array}{l}\text { Chemical, } \\
\text { organic }\end{array}$ & $\begin{array}{l}\text { Tall-oil } \\
\text { based }\end{array}$ & $\begin{array}{l}\text { Tall-oil } \\
\text { based }\end{array}$ \\
\hline
\end{tabular}

${ }^{1}$ The $0 \%$ mixtures are based on [38]. ${ }^{2}$ The $71 \%$ mixtures are a regression based on the $93 \%$ mixtures, in which the material proportions are kept constant independently from their origin (primary or secondary), but the amount of RAP varies. ${ }^{3}$ The $93 \%$ mixtures are based on [16].

The compositions of the PA, SMA, and AC bin/base mixtures at $0 \%, 58 \%, 71 \%$, and 93\% RAP are shown in Table 2. These percentages are presented as the minimum and maximum RAP content and when a change in production technology is entailed (WMA with additives and bitumen foaming, respectively). The compositions of all mixtures are given in Supplementary Material Table S3. 


\subsubsection{Energy Calculations \\ Heating Requirements}

The heating requirements to produce asphalt, which are displayed in Table 3, depend on the temperature difference between the unheated and heated materials, the heat capacity of the materials in the mixture composition, and the moisture content. In this study, we used the approaches presented by $[5,15]$, which take into account the temperature dependency of the heat capacities. Note that the heat capacity for water (hardly) changes with temperature, and was therefore assumed to be constant.

Table 3. Energy consumption of the production of one tonne of asphalt for different shares of RAP content.

\begin{tabular}{|c|c|c|c|c|c|c|c|c|c|c|c|c|}
\hline \multirow{2}{*}{ Raw Material } & \multicolumn{4}{|c|}{ PA } & \multicolumn{4}{|c|}{ SMA } & \multicolumn{4}{|c|}{ AC Bin/Base } \\
\hline & $0 \% 1$ & $58 \%$ & $71 \%^{2}$ & $93 \%^{3}$ & $0 \% 1$ & $58 \%$ & $71 \%^{2}$ & $93 \%^{3}$ & $0 \% 1$ & $58 \%$ & $71 \%^{2}$ & $93 \%$ RAP $^{3}$ \\
\hline Final temperature $\left({ }^{\circ} \mathrm{C}\right)$ & 175 & 135 & 105 & 105 & 175 & 135 & 105 & 105 & 175 & 135 & 105 & 105 \\
\hline Diesel (MJ) & 15.81 & 15.81 & 15.81 & 15.81 & 15.81 & 15.81 & 15.81 & 15.81 & 7.39 & 7.39 & 7.39 & 7.39 \\
\hline Electricity $^{5}(\mathrm{kWh})$ & 7.99 & 3.89 & 15.58 & 17.58 & 6.29 & 2.42 & 11.91 & 11.75 & 15.13 & 4.67 & 10.72 & 10.72 \\
\hline Natural Gas ${ }^{4}(\mathrm{MJ})$ & 240.5 & 202.7 & 165.5 & 160.5 & 240.3 & 203.1 & 170.5 & 171.0 & 251.7 & 209.1 & 174.7 & 174.7 \\
\hline
\end{tabular}

${ }^{1}$ The $0 \%$ mixtures are based on [38]. ${ }^{2}$ The $71 \%$ mixtures are a regression based on the $93 \%$ mixtures, in which the material proportions are kept constant independently from their origin (primary or secondary), but the amount of RAP varies. ${ }^{3}$ The $93 \%$ mixtures are based on [16]. ${ }^{4}$ The natural gas needs were calculated according to the heat capacity of the components of the asphalt mixture, as explained in the subsequent equations. The electricity consumption is given by the amount needed to heat up bitumen up to the temperature specified for the asphalt mix plus a constant amount according to [38]. ${ }^{5}$ Part of the electricity accounted for in the asphalt mix production corresponds to general asphalt plant operation, which is not dependent on asphalt type; therefore, it was kept constant for all asphalt mixes at $10.23 \mathrm{kWh}$.

The energy for heating was calculated as a sum of the need for heating the rock aggregates plus the energy needed to heat the bitumen. The heating energy $E_{\text {heating }}$ needed for bitumen was calculated as a combination of the heat required for diverse oil components and water present in the mix. For that purpose, Equation (1) was used:

$$
\begin{gathered}
E_{\text {heating }}=\left(\sum_{i} m_{i} \times \int_{T_{0, i}}^{T m i x} C_{i, T} d T+\sum_{i} m_{i} \times f_{w, i} \times C_{w} \times\left(100-T_{0, i}\right)+\sum_{i} m_{i}\right. \\
\left.\times f_{w, i} \times L_{v}+\sum_{i} m_{i} \times f_{w, i} \times C_{\text {vap }} \times\left(T_{\text {mix }}-100\right)\right) \times(1+C L)
\end{gathered}
$$

(adapted from: [5])

where

- $\quad m_{i}$ is the mass of a mixture component $i$; (RAP, gravel, sand, or filler);

- $T$ is the temperature $\left(\right.$ in $\left.{ }^{\circ} \mathrm{C}\right)$ either at the start $\left(T_{0}=15^{\circ} \mathrm{C}\right.$ ) or after heating the mix (T mix);

- $\quad C_{i, T}$ is the specific heat capacity $\left(\mathrm{kJ} /{ }^{\circ} \mathrm{C} / \mathrm{kg}\right)$ of component $i$ as a function of the temperature $T$;

- $\quad f_{w, i}$ is the fraction of water in component $i$;

- $C_{w}$ is the specific heat capacity of water $\left(\mathrm{kJ} /{ }^{\circ} \mathrm{C} / \mathrm{kg}\right)$, assumed to be constant at $4.19 \mathrm{~kJ} /{ }^{\circ} \mathrm{C} / \mathrm{kg}$ );

- $\quad L_{v}$ is the latent heat of water evaporation $(\mathrm{kJ} / \mathrm{kg})$;

- $C_{\text {vap }}$ is the specific heat capacity of water vapor $\left(\mathrm{kJ} /{ }^{\circ} \mathrm{C} / \mathrm{kg}\right)$, assumed to be constant at $1.83 \mathrm{~kJ} /{ }^{\circ} \mathrm{C} / \mathrm{kg}$ );

- $C L$ represents the energy lost to the atmosphere via the casing of the drums in the asphalt plant (constant at 17.8\%, derived from the casing losses reported in Santos et al. [5], which neglect temperature dependency, and our own recalculation including temperature dependency based on Santos et al. [15]).

Ref. [5] does not report values for casing losses; however, in [15], casing losses of $27 \%$ are reported. These are calculated as the difference between the theoretically derived energy consumption and the actual consumption. Redoing the calculations in [15] with 
Equation (1), we found that the modelled energy use is $7.8 \%$ higher if one takes into account the temperature dependency of the specific heat capacities. Based on this finding, we used a corrected value for the casing losses of $17.8 \%$ (i.e., $27 \% / 7.8 \%$ ).

The heat capacity as a function of the temperature for rocks and minerals is given by Equations (2) and (3):

$$
C_{i, T}=C_{i, r e f} \times\left(C_{i, n o r m, T} / C_{i, n o r m, r e f}\right)
$$

where

- $\quad C_{i, T}$ is the calculated specific heat capacity at a given temperature $T$;

- $C_{i, r e f}$ is the measured specific heat capacity obtained in the literature;

- $\quad C_{i, n o r m, T}$ is the normalized heat capacity at a given temperature $T$;

- $C_{i, n o r m, r e f}$ is the normalized heating capacity at the reference temperature.

The normalized heat capacity $\left(C_{i, n o r m}\right)$ at any temperature can be calculated with a regression derived by Waples and Waples [39], as shown in Equation (3):

$$
C_{i, n o r m, r o c k s, T}=8.95 \times 10^{-10} T^{3}-2.13 \times 10^{-6} \times T^{2}+0.00172 \mathrm{~T}+0.716
$$

where

- $C_{i, n o r m, r o c k s, T}$ is the normalized heat capacity of a rock at temperature $T$.

According to [39], this equation is unitless and can be used for calculating the specific heat capacity of any mineral or nonporous rock at any unit and temperature if a measured value of specific heat capacity is provided at any temperature and the same units $\left(C_{i, \text { ref }}\right)$. The heat capacities are given in the Supplementary Material (Table S2).

For oils, the specific heat capacity can be directly calculated using Equation (4):

$$
C_{i, T, o i l s}=2092 S^{0.5} \times 2.9297 T-43.7
$$

(from: [40])

where $S$ is the specific gravity of the oil (unitless). The specific gravity of oils present in bitumen is given in the Supplementary Material (Table S2) along with the heat capacities of the aggregates and water.

\section{Heating Mixtures with RAP}

When reclaimed asphalt pavement is used, the recycled granulate is heated in a parallel drum to a to prevent further aging of the binder. In order to compensate for this suboptimal temperature, the virgin materials have to be overheated. In this study we assumed the maximum temperature to which RAP is pre-heated is $120^{\circ} \mathrm{C}$ for the mixtures containing up to $58 \%$ RAP. The maximum temperature to which the virgin material can be heated safely is set at $250{ }^{\circ} \mathrm{C}$, which corresponds to a maximum fraction of RAP of $58 \%$. For higher percentages of RAP, we assume that the use of chemical WMA additives is necessary to lower the desired mix temperature to $135^{\circ} \mathrm{C}$. For even higher percentages of RAP, such as $93 \%$, the temperature has to be lowered to $120^{\circ} \mathrm{C}$ or less. In this study a final mix temperature of $105^{\circ} \mathrm{C}$ was used. The temperature required for the virgin materials can be calculated as follows:

- $1 \%-58 \%$ RAP: final temperature: $175^{\circ} \mathrm{C}$, RAP temperature: $120^{\circ} \mathrm{C}$, virgin (overheating) temperature: Equation (5), $\max 250^{\circ} \mathrm{C}$;

- 58\%-70\%: final temperature: $135{ }^{\circ} \mathrm{C}$, RAP temperature: $120{ }^{\circ} \mathrm{C}$, no overheating required;

- $71 \%-93 \%$ : final temperature: $105{ }^{\circ} \mathrm{C}$, RAP temperature: $105{ }^{\circ} \mathrm{C}$, no overheating required.

The temperature required for the virgin materials can be calculated as follows:

$$
T_{\text {virgin material }}=\left(T_{\text {mix }}-\left(T_{R A P} \times f_{R A P}\right)\right) /\left(1-f_{R A P}\right)
$$


(from: [38])

where $T$ is the temperature to which the virgin material, the asphalt mixture, and RAP are heated, respectively, and $f_{R A P}$ is the (mass) fraction of RAP in the asphalt mixture. The overheating and final temperatures depending on RAP are given in Table 3.

\subsubsection{Energy Mix for 2030}

As it will take time before these mixtures with high RAP content are on the market, calculations have also been performed for a situation in 2030 with expected changes in energy supply. Two exogenous changes are expected to occur in the coming years that will affect the carbon footprint of asphalt production: a change in the electricity mix and a change in the transport fleet. The energy sources in the Dutch electricity mix for 2030 were estimated by [41] (Table 4). Ecoinvent processes used for the modelling are shown in Table 4. To reflect expected improvements in transport efficiencies, lorry transport complying with EURO 6 norms (in contrast to EURO 5) was assumed.

Table 4. Percentages of energy sources for electricity generation in the Netherlands [41].

\begin{tabular}{cc}
\hline Electricity & $\mathbf{2 0 3 0}$ \\
\hline Natural gas (and other fossil) & $28 \%$ \\
Coal & $0 \%$ \\
Nuclear & $3 \%$ \\
Wind & $48 \%$ \\
Sun & $18 \%$ \\
Biomass & $2 \%$ \\
\hline
\end{tabular}

\section{Results}

\subsection{Carbon Footprints 2020}

The carbon footprints of the three mixtures with increasing RAP contents with the 2020 electricity mix are shown in Figure 1. The carbon footprints decreased from about 70 to about $45 \mathrm{~kg} \mathrm{CO}$ eq. $/ \mathrm{t}$ for $\mathrm{AC}$ bin/base, from about 90 to $45 \mathrm{~kg} \mathrm{CO}_{2}$ eq. $/ \mathrm{t}$ for SMA, and from about 95 to about $35 \mathrm{~kg} \mathrm{CO}$ eq./t for PA surface mixes. Figure 1 also clearly shows the increased uncertainty with decreasing TLR and more demanding asphalt layers. Even including uncertainty, carbon footprint reductions are expected from 30\% RAP for AC bin/base and from $71 \%$ RAP for SMA and PA. On the other hand, uncertainty estimations showed that for some future technologies, carbon footprints might be as high as for the current situation. Therefore, continuous improvement of LCA estimates is needed through the development process and for application to new layers.

\subsubsection{Contributions to Carbon Footprint}

The three mixes with $0 \%$ RAP showed primary materials as the biggest contributors to their carbon footprints, followed by the energy consumption of warming up the asphalt materials during the production phase. With increasing RAP content, the contribution of primary materials to total carbon footprint decreased, and at about 70\% RAP for SMA and PA, it was reduced to about $50 \%$, while the other $50 \%$ comes from energy requirements and transport. At $93 \%$ RAP content, the energy consumption contributed most to the carbon footprints of all mixtures.

For PA and SMA, Figure 1 shows that the carbon footprint contribution of additives increases gradually. For mixtures containing between $45 \%$ and $70 \%$ of RAP, additives contributed up to $10 \%$. For mixtures containing $71 \%$ to $93 \%$ RAP, additives contributed up to $9 \%$ to the carbon footprint. Even for the AC bin/base with $93 \%$ RAP, the additives contributed less than $5 \%$ to the carbon footprint because the mass used is relatively small. The mass of additives varies according to the percentage of bitumen in the asphalt mixture, and its impact varies accordingly. SMA mixtures tend to need more bitumen when compared to AC or PA mixtures; consequently, SMA mixtures have a higher carbon footprint from additives. 


\section{AC bin/base}
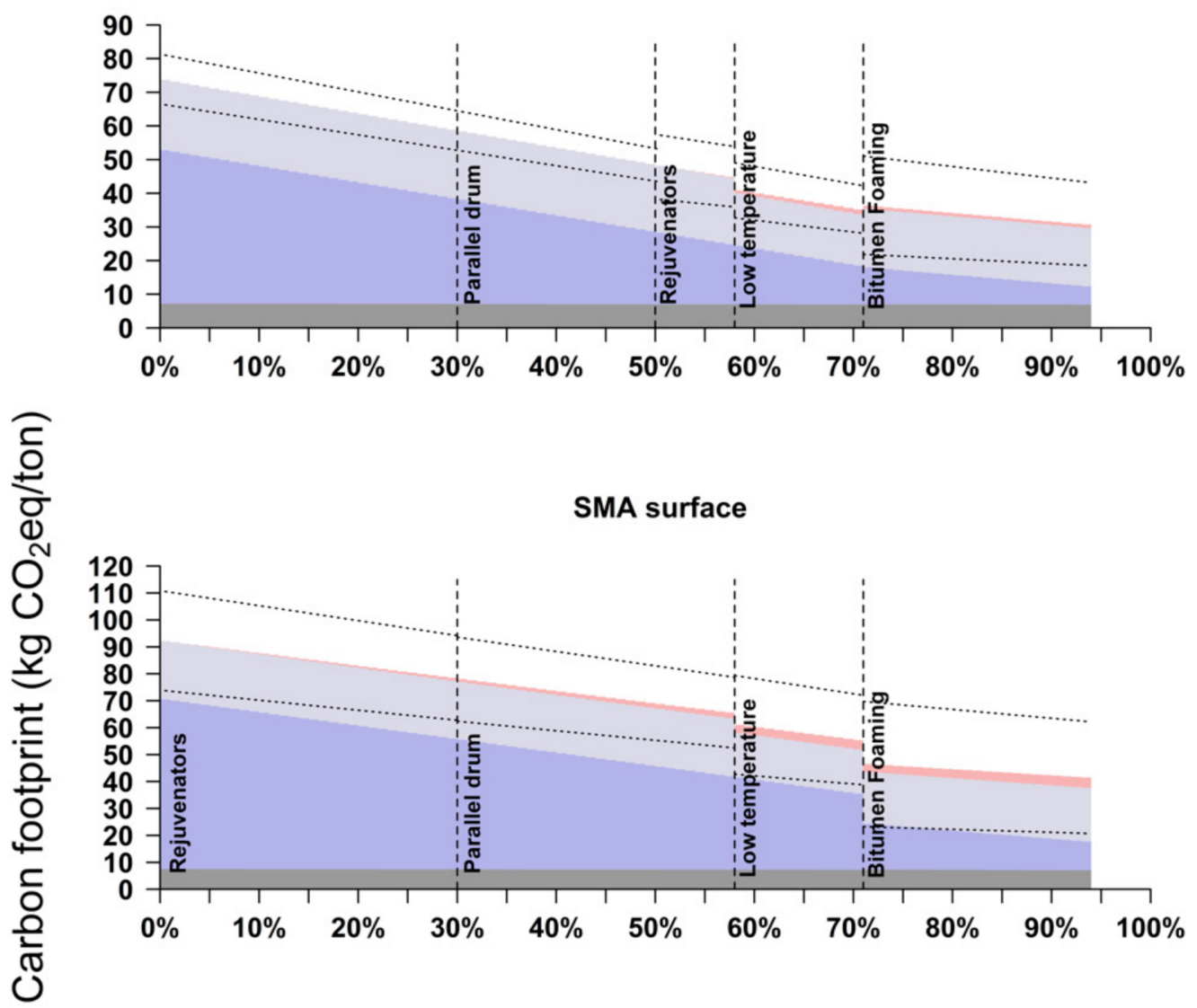

PA surface

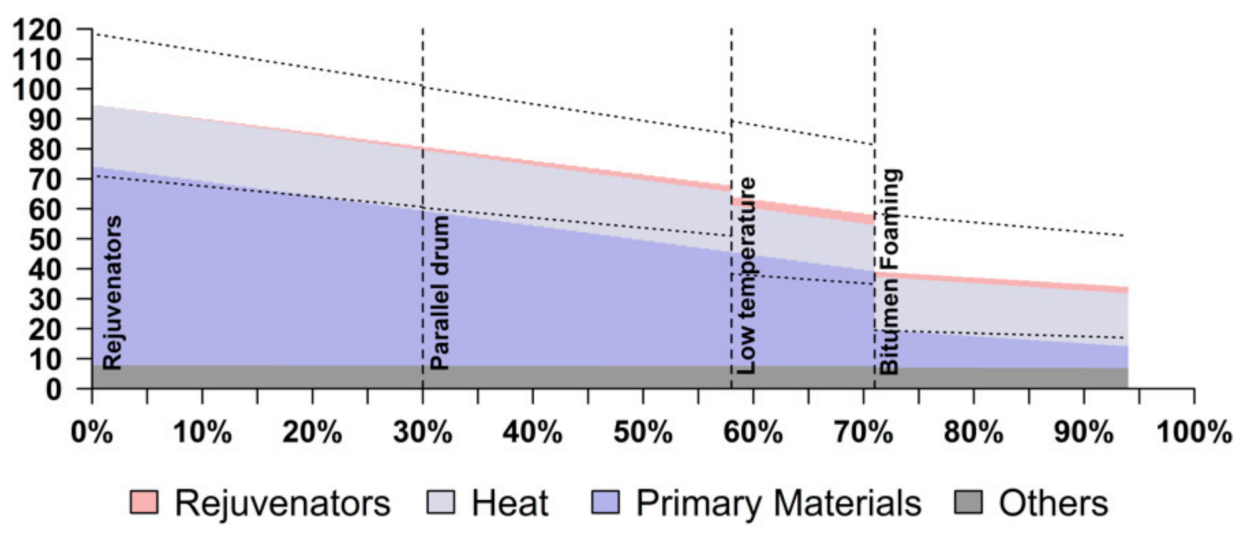

\section{Reclaimed Asphalt Percentage}

Figure 1. Carbon footprints ( $\mathrm{kg} \mathrm{CO}_{2}$ eq./t) of the three asphalt mixtures-asphalt concrete for the binder and base layers (AC bin/base), stone mastic asphalt (SMA), and porous asphalt (PA)—for increasing percentages of RAP content in 2020. The estimated uncertainty range based on the TRL and asphalt layer is also shown (dotted lines). Vertical dashed lines indicate where a change in technology is required to achieve higher RAP contents. The category "Heat" comprises the carbon footprint of natural gas and electricity needed. The category "Others" relates to the footprint of road transport, electricity consumption from asphalt plant operation, which is independent from asphalt mix, and diesel consumption of cranes, excavators, and stone crushers. 


\subsubsection{Reduction Potential}

Up to a recycled content of $58 \%$, all savings in terms of carbon footprint were due to the reduction of primary raw material consumption. Mixtures containing $58 \%-70 \%$ recycled content require lower temperatures during production. Lowering the production temperature to $135{ }^{\circ} \mathrm{C}$ and adding increasing fractions of RAP (up to $70 \%$ ) led to an additional carbon footprint reduction of up to $9 \%$.

Figure 1 shows a reduction in the carbon footprint of AC bin/base of $35 \%$ for $50 \%$ RAP mixtures compared to the $0 \%$ RAP mixture. However, as AC bin/base containing $50 \%$ RAP is the standard in the Netherlands, an additional reduction can only be achieved with higher RAP percentages.

SMA with 71\% RAP and 93\% RAP had, respectively, 50\% and 55\% lower carbon footprints compared with SMA containing $0 \%$ RAP. Finally, carbon footprint reductions of $59 \%$ and $64 \%$ were calculated for PA containing $71 \%$ RAP and $93 \%$ RAP compared to the mixture containing $0 \%$, respectively, the first being produced with WMA technology and the second with foamed bitumen. Producing AC bin/base at $135{ }^{\circ} \mathrm{C}(\mathrm{WMA})$ and then at $105{ }^{\circ} \mathrm{C}$ using foamed bitumen technology delivered a further $25 \%$ and $36 \%$ reduction of the carbon footprint compared to the 50\% RAP variant (58\% reduction compared to $0 \% \mathrm{RAP}$ ).

For RAP percentages above 70\%, additional measures are necessary to keep the quality of the asphalt constant, such as sieving. While sieving has a negligible impact on the carbon footprint, it allows a better asphalt mix design, which results in a high-quality asphalt that can be used in intense-traffic roads. The production of a 93\% RAP asphalt mix of high quality is only possible through this production step, which was included in the total electricity consumption of the asphalt plant. At 71\% RAP content in the SMA and PA mixtures, the carbon footprint of primary material use decreased by more than $70 \%$ compared to the $0 \%$ RAP mixtures, and the total footprint reduction reached $50 \%$ for SMA and $59 \%$ for PA compared to their $0 \%$ RAP counterparts. However, because the electric heat requirement increases due to the bitumen foaming, it hampers the reduction in the carbon footprint for $\mathrm{AC}$ bin/base. Furthermore, $1 \mathrm{MJ}$ heat generated by burning natural gas on site has a lower carbon footprint $(0.07 \mathrm{~kg} \mathrm{CO}$ eq.) than $1 \mathrm{MJ}$ heat generated using electricity from the country mix $(0.14 \mathrm{~kg} \mathrm{CO}$ eq.). AC bin/base is the most affected mixture because it demands a relatively higher amount of fine materials than the other two mixtures, and these fine materials that are present in RAP are rich in bitumen and participate in the bitumen foaming, which, in turn, uses electricity for its heating process.

\subsection{Carbon Footprint 2030}

Figure 2 shows the carbon footprints of the three mixtures with increasing RAP contents using the 2030 scenario for electricity and transport. This electricity scenario is especially relevant to the asphalt mixtures produced with foamed bitumen technology, since the primary bitumen and the fine, bitumen-rich secondary aggregate are warmed up using electricity. While electricity contributed up to $37 \%$ for the mixtures with the highest RAP content in the 2020 scenario, in the 2030 scenario, it contributed between $8 \%$ and $13 \%$.

Achievable reductions for AC bin/base mixtures containing between $71 \%$ and $93 \%$ RAP content were slightly higher in relation to their SMA and PA counterparts because of the higher amount of fine materials being heated with the use of an electric machine. This indicates that for a further reduction of carbon footprints of asphalt mixtures, heating sources with much lower carbon footprints are required than currently expected for the Dutch electricity mix.

It is important to highlight that the 2030 electricity scenario adds another layer of uncertainty to the model. Policy directives regarding carbon footprint reduction measures for electricity production and others can change in the coming years, affecting the abovementioned results. 


\section{AC bin/base}
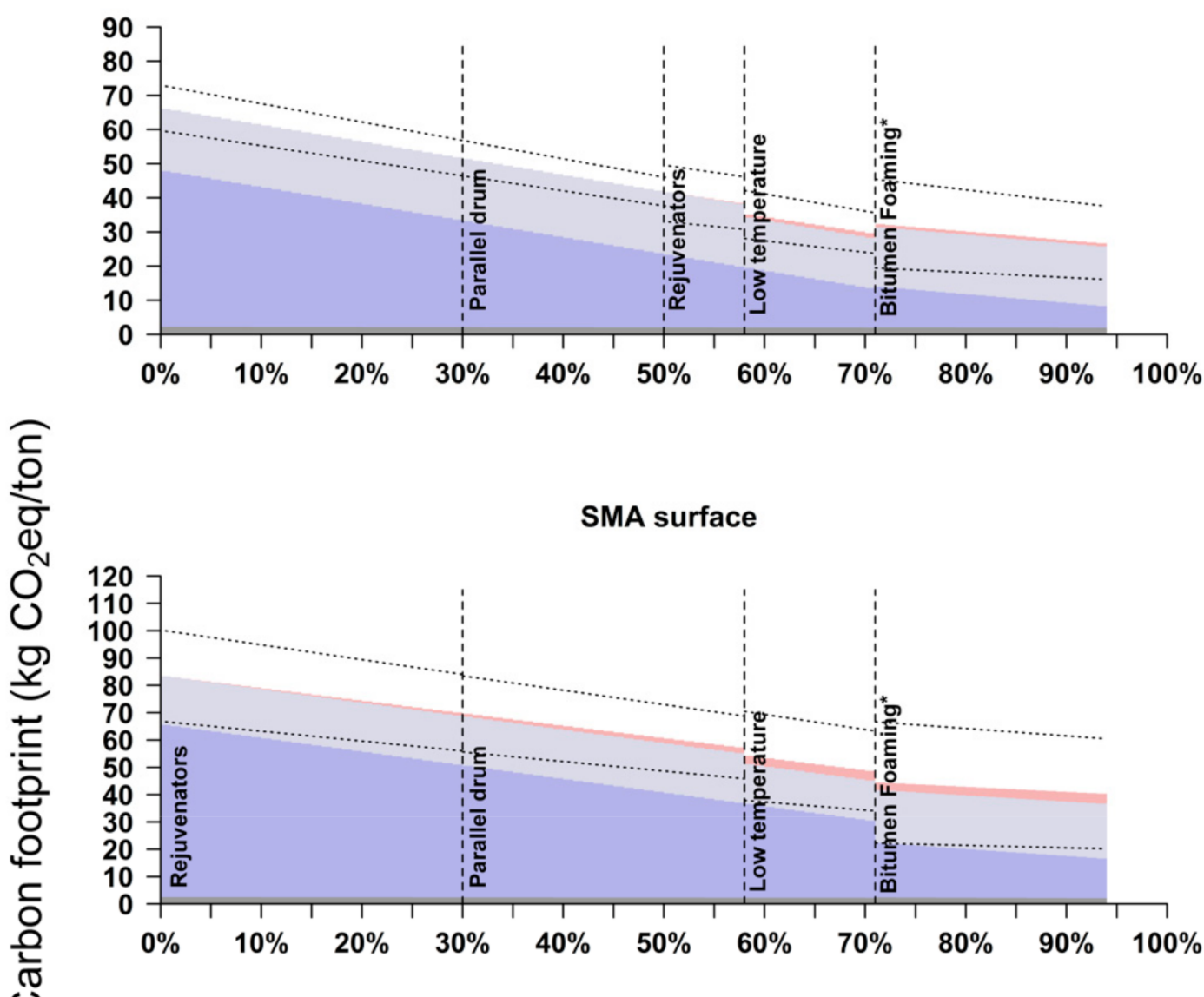

PA surface

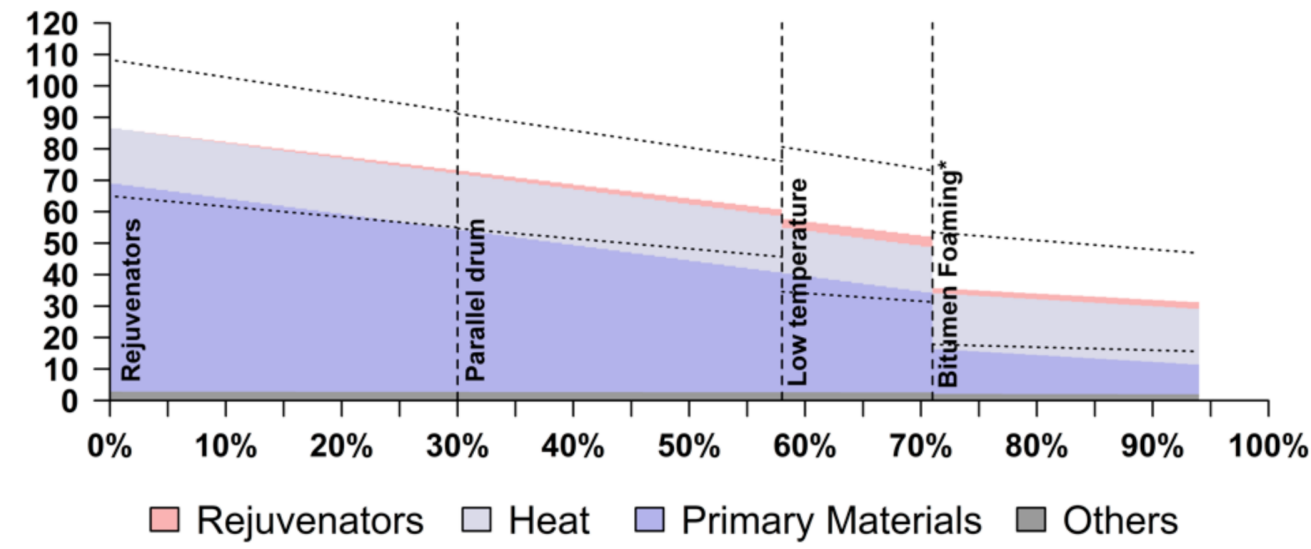

Reclaimed Asphalt Percentage

Figure 2. Carbon footprints ( $\mathrm{kg} \mathrm{CO}_{2}$ eq./t) of the three asphalt mixtures-AC bin/base, SMA, and PA-for increasing percentages of RAP content, considering an electricity mix and road transport scenario for the Netherlands in 2030 according to approved legislation. The category "Heat" comprises the carbon footprint of natural gas and electricity needed. The category "Others" relates to the footprint of road transport, electricity consumption from asphalt plant operation, which is independent from the asphalt mix, and diesel consumption of cranes, excavators, and stone crushers. 


\section{Discussion}

Over the past decades, several authors have assessed the carbon footprints of asphalt mixtures with different RAP contents. Most studies have explored the footprint effects of mixtures of up to $50 \%$ RAP content, and none of them have shown the effects of the technological leaps that are necessary to reach those percentages. For $45 \%-60 \%$ RAP contents, Refs. $[13,22,24,42]$ found reductions in carbon footprints of $5 \%-57 \%$. For the same RAP content, we found a reduction potential from $23 \%$ to $46 \%$. Ref. [17] found carbon footprint reductions of $20 \%$ to $40 \%$ for RAP contents between $25 \%$ and $100 \%$. For RAP contents from $20 \%$ to $93 \%$, we found a reduction potential from $14 \%$ to $64 \%$. The carbon footprint reduction varies greatly between these studies because they are defined for a specific road section and a specific project and use diverse impact assessment methods, life-cycle scenarios, and system boundaries. Consequently, the detailed results are hard to compare.

The carbon footprint reduction of $25 \%$ for SMA and PA and 35\% for AC bin/base described previously is within the range reported by [22], who reported results for mixes of asphalt concrete applied to the surface, binder, and base layers. He used a similar functional unit, system boundaries, and carbon footprint assessment method to calculate the impacts of his asphalt mixtures, and concluded that the surface and binder layers performed similarly regarding their footprint reduction.

It is possible to reduce the carbon footprint of asphalt in relation to current standard production methods by reducing the mixing temperature during production to $150^{\circ} \mathrm{C}$ or lower. Asphalt mixtures produced under these conditions are WMAs. Ref. [42] investigated the potential carbon footprint reduction of WMA produced at $100{ }^{\circ} \mathrm{C}$ in comparison to an HMA produced at $165{ }^{\circ} \mathrm{C}$. He found a footprint reduction of approximately $33 \%$. Likewise, Ref. [11] compared the footprint of WMA produced using zeolite and HMA. In his study, the benefits of lowering the production temperature were offset by the use of zeolite, resulting in similar carbon footprints for both mixtures. A reduction of only $13 \%$ occurred if the WMA was produced with $15 \%$ RAP content. Furthermore, Ref. [12] reported a carbon footprint reduction of approximately $6 \%$ for WMA in comparison to HMA, but also highlighted that the biggest footprint reduction (15\%) was achieved when RAP was introduced in the WMA. The reduction was associated with the environmental burdens of bitumen, filler, and zeolite-based additives. Comparing the carbon footprint of heating for the HMA $0 \%$ RAP AC bin/base mixture produced at $175^{\circ} \mathrm{C}$ to the WMA $58 \%$ RAP AC bin/base mixture produced at $135^{\circ} \mathrm{C}$ in Figure 1, a carbon footprint reduction of approximately $8 \%$ can be seen. This reduction is solely due to the lower production temperature; similarly, for SMA and PA, there is a reduction of approximately $3 \%$. Thus, our results are similar to the ones found by [12] and the other studies mentioned above.

\subsection{Limitations of the Study}

Some important aspects of the life cycle of an asphalt mixture were not included in this study. One of them is the possible difference in technical performance of asphalt mixtures, the most important difference being service life. The service life varies according to the asphalt type, the traffic, and the types of vehicles driving on it.

The service life of an asphalt mixture is key to determine whether a certain modification results in a reduction or increase in environmental impacts. Refs. [6,14] stated that incorporating RAP in asphalt mixtures is beneficial, provided that their service life remains comparable to the $100 \%$ primary ones. Ref. [15] verified that a shorter service life time increases the environmental burdens associated with asphalt production due to the more frequent maintenance and rehabilitation activities. Ref. [24] assessed the footprints of different asphalt alternatives containing RAP for an airport runway rehabilitation, and found that the environmental benefits of using RAP were offset if the service life of those mixtures was $7 \%$ shorter than its counterpart based on $100 \%$ primary materials.

In this study, we assumed that RAP-containing mixtures have the same technical performance and service life as the $100 \%$ primary mixtures, which is in line with $[11,12]$ 
and is supported by results of tests by the RWS that used WMA porous asphalt with 93\% RAP and demonstrated no performance loss $[43,44]$. However, it is important to highlight that if future research shows that the technical performance of RAP mixtures is worse than that of the current standard mixtures, it could cause the asphalt carbon footprint to increase rather than decrease.

Another point where there is no consensus when it comes to asphalt LCAs is determining the system boundaries, especially when RAP is used. From all the studies listed in the previous section, it has become clear that different approaches for the end of life of asphalt mixtures are used. Ref. [45] includes asphalt milling, transportation, and other processing activities as environmental burdens for RAP, while Ref. [11] considers RAP a waste material that is consequently free of environmental burdens. Refs. [12,22] use an intermediate approach that includes environmental burdens generated after RAP reaches the end-of-waste status, such as transport of RAP from the construction site to the asphalt plant and crushing. This is also the approach used in this study and is in line with the EN 15804 and the Dutch product category rules for asphalt. Approaching the system boundaries of RAP in different ways may change the results and conclusions of systems that are very sensitive to RAP content, which is the case for this study. The EN 15804 and the EN 17932-1 are complementary norms that define clear rules for the modelling of mixtures that include RAP in their composition, consequently reducing uncertainties related to the definition of system boundaries.

Our study focussed on carbon footprint only. However, considering other impact categories could show whether burden shifting occurs between them. For example, Ref. [15] showed the terrestrial ecotoxicity results for a WMA with $0 \%$ RAP and a WMA with $50 \%$ RAP produced at $130{ }^{\circ} \mathrm{C}$ using an additive. The additive completely offset the environmental benefits of reducing the mixing temperature of the asphalt and using $50 \%$ RAP content in comparison to the HMA $\left(160^{\circ} \mathrm{C}\right)$ in all impact categories. On the other hand, the other categories reported in the study were not significantly affected by the use of the additive and showed an improvement. That is also in line with the findings from [14], who reported impact reduction across all the impact categories present in the International Reference Life Cycle Data System (ILCD) method when RAP was incorporated into HMA. We conclude that our study might miss some problem-shifting issues in terms of toxicity versus climate change, but no other major issues are expected.

Finally, our calculations only showed the effects of surfactants and pine needle oil as additives. However, several techniques are available to ensure the performance of mixtures containing RAP. Different additives can have different environmental profiles that could affect the carbon footprints of different mixtures and, consequently, some results of this study. Ref. [46] showed the energy consumption and carbon footprint reductions achieved with the production of WMA using a chemical additive (surfactant) and an organic wax additive, in which both additives contributed to a lower footprint, but the chemical additive had better results. No comparison of environmental profiles of high RAP contents with different additives has been found. It is thus hard to say how other additives could influence this study's results.

Lastly, no other aspects of the life cycle of asphalt were investigated, such as social aspects like noise or economic aspects such like direct costs. However, a combined approach can help decision makers and stakeholders to understand the economic consequences of new asphalt technologies and to find compromises to reach the best performance in all aspects, as demonstrated by [5] in his methodology.

\subsection{Recommendations}

We estimated that asphalt containing $93 \%$ RAP and mixed at $105^{\circ} \mathrm{C}$, which is based on [16], would lead to a reduction in the carbon footprint of more than $60 \%$, or $31 \mathrm{~kg}$ $\mathrm{CO}_{2}$ eq. emissions per tonne. Producing mixtures with 93\% RAP content reduces the material carbon footprint of the three asphalt mixtures studied by more than $83 \%$. As shown in Figure 1, with 93\% recycled materials, between $17 \%$ and $25 \%$ of the carbon 
footprint (between 5.4 and $10.7 \mathrm{~kg} \mathrm{CO}$ eq.) was caused by the production of materials, while $50 \%$ was caused by the energy requirements (between 24.1 and $26.7 \mathrm{~kg} \mathrm{CO}_{2}$ eq.). Therefore, for further reduction of the carbon footprint, less energy use or use of energy with a lower carbon footprint is needed. Ref. [15] presented a scenario with an alternative energy source for asphalt plants-natural gas instead of heavy fuel oil. However, using a combination of natural gas and electricity is already standard in the Netherlands, where companies are now developing other strategies to further reduce their carbon footprints. Figure 2 in this study includes an energy mix scenario for the electricity production in the Netherlands in 2030 in line with current policy, which has an influence on the foamed bitumen mixtures, which rely on electricity for the foaming process; however, possible energy sources for heat other than natural gas and the use of other types of machinery in asphalt plants (now fuelled by diesel) are now considered parts of plant-specific strategies to lower their carbon footprints and should be assessed in the same way as RAP content.

Our calculations showed potential carbon emission savings for asphalt using reclaimed pavement (up to $67 \%$ ), but not all the technologies have yet been made widely available or been tested in the long term under real-life conditions. The mixtures containing more than $70 \%$ RAP have a TRL that is estimated to be 4 or 5 , since the first tests have been performed in labs and now at a small scale on roads. Therefore, we can conclude that high-RAP-content mixtures are not common, but are under development. However, they were included in this study because the Dutch road authority has been investing in new technologies that enable the production of asphalt mixtures with high RAP content. Recently, an asphalt mixture including 50\% RAP was certified in the Netherlands by a board of specialists [47], and road sections have recently been paved with 70\% RAP content for further testing [48].

Increasing RAP content in asphalt mixtures can reduce their service life, but achieving comparable lifetimes of the asphalt layers is essential for reaching the reduction potential estimated in this research. Refs. [49,50] mention that the higher stiffness of the RAP could affect the performance of the asphalt mixtures, such as with crack propagation increase and fatigue resistance decrease. The moisture content of the RAP is another point of concern that could also affect the service life of the asphalt layer [24]. The rutting performance of RAP-containing layers could be lowered by the lower temperatures and higher moisture susceptibility $[13,49]$. Refs. [50,51] showed comparable performance results that were comparable to HMA for WMA-RAP using different additives, except for moisture susceptibility [50].

The performance of mixtures with even higher RAP contents and, accordingly, lower final mixing temperatures needs further investigation, along with an analysis of the different additives available in the market, considering the whole life cycle of asphalt.

The transport phase can also have a considerable impact on the carbon footprints of asphalt mixtures [4]. Therefore, sourcing materials locally and using cleaner transport modes could also help decrease the footprint of asphalt. Using RAP may bring another environmental benefit due to the reduction of transport distances for sourcing raw materials, since it tends to be closer to the asphalt plants than the currently used primary aggregates, according to [22]. However, the impacts of transport were not explored in detail in this study.

\section{Conclusions}

We used an approach to estimate the potential carbon footprint of asphalt innovations that consisted of first defining the environmental profiles of current state-of-the-art technologies, then investigating technological innovations, and, finally, modelling the resulting deviations in asphalt mixtures from the references. We also included first-order uncertainty estimates based on the TRLs of the technologies. Three mixtures with different applications were assessed, namely a binder mixture (AC bin/base) and two wearing-course mixtures (SMA and PA). Next, the technology leaps necessary to achieve the desired RAP content were investigated and their effects were quantified. 
Warm-mix asphalt using additives that enable production at temperatures as low as $135^{\circ} \mathrm{C}$ and foamed bitumen with a mixing temperature of $105^{\circ} \mathrm{C}$ using a tall-oil-based additive delivered the largest reductions in carbon footprints in combination with RAP contents above 71\%. AC bin/base, SMA, and PA reached footprint reductions of 58\%, 55\%, and $64 \%$, respectively, when compared to their HMA $0 \%$ RAP content counterparts.

Considering the energy scenario of 2030 for the Netherlands, these footprints could be further reduced by up to $10 \%$. Nevertheless, even with a more sustainable electricity mix, the energy consumption of asphalt production will remain the highest footprint contributor.

It is important to consider the limitations of this study together with the results that were presented.

This study presents a cradle-to-gate analysis and, consequently, disregards the possible service life effects of incorporating RAP and its impacts on the carbon footprint. As evidenced by previous studies and several authors, a shorter service life can easily offset any environmental benefits of incorporating secondary materials in new asphalt mixtures.

The system boundaries differ largely among asphalt LCAs, which limits the comparability and validation of findings between them. However, the system boundaries' uncertainties and comparability are largely increased when the international norms and their complements are followed. Our study was performed in line with the EN 14804 and the EN 17932-1.

The carbon footprint was chosen as the focus for the assessment of the potential of new asphalt production technologies, meaning that burden shifting between impact categories was disregarded. This could be specially relevant in the case of ecotoxicity for mixtures that make use of additives.

Lastly, the carbon footprint of only one type of additive was investigated for each mixture, which did not allow the comparison of the profiles of RAP mixtures that contain different types of additives available in the market, which most likely have different carbon footprints.

Regarding the inclusion of high percentages of RAP in new asphalt mixtures, it is important to consider its moisture content, which could affect the lifetime of the asphalt layer and the energy consumption during production [24]. The rutting performance of RAP-containing layers could also be lowered by the lower temperatures and higher moisture susceptibility $[13,49]$, causing a service life reduction and possibly reverting the environmental benefits of using RAP [24].

Supplementary Materials: The following are available online at https:/ / www.mdpi.com/2071-105 0/13/3/1382/s1, Table S1: Carbon footprints of the used materials and the process inputs calculated using their corresponding processes in the EcoInvent 3.5 cut-off database or other sources according to the SBK Bepalingsmethode (v.3.04 July 2020) impact assessment method based on the EN 15804, Table S2: Table of specific heat for asphalt mix components at $20^{\circ} \mathrm{C}$ as given in [15] and specific gravity of bitumen from [40], Table S3: Composition of asphalt mixtures from $0 \%$ up to $93 \%$ RAP content.

Author Contributions: All authors contributed to the current paper. Conceptualization, D.E.G.B., Z.S., and M.H.; methodology, D.E.G.B., Z.S., and M.H.; formal analysis, D.E.G.B. and M.H.; investigation, D.E.G.B. and M.H.; resources, D.E.G.B. and M.H.; data curation, D.E.G.B. and Z.S.; writing-original draft preparation, D.E.G.B. and Z.S.; writing-review and editing, E.K. and I.N.; supervision, M.H. All authors have read and agreed to the published version of the manuscript.

Funding: This research received no external funding.

Acknowledgments: The authors appreciate the support and insights provided by Suzanne De Vos-Effting from Rijkswaterstaat on asphalt innovations.

Conflicts of Interest: The authors declare no conflict of interest. 


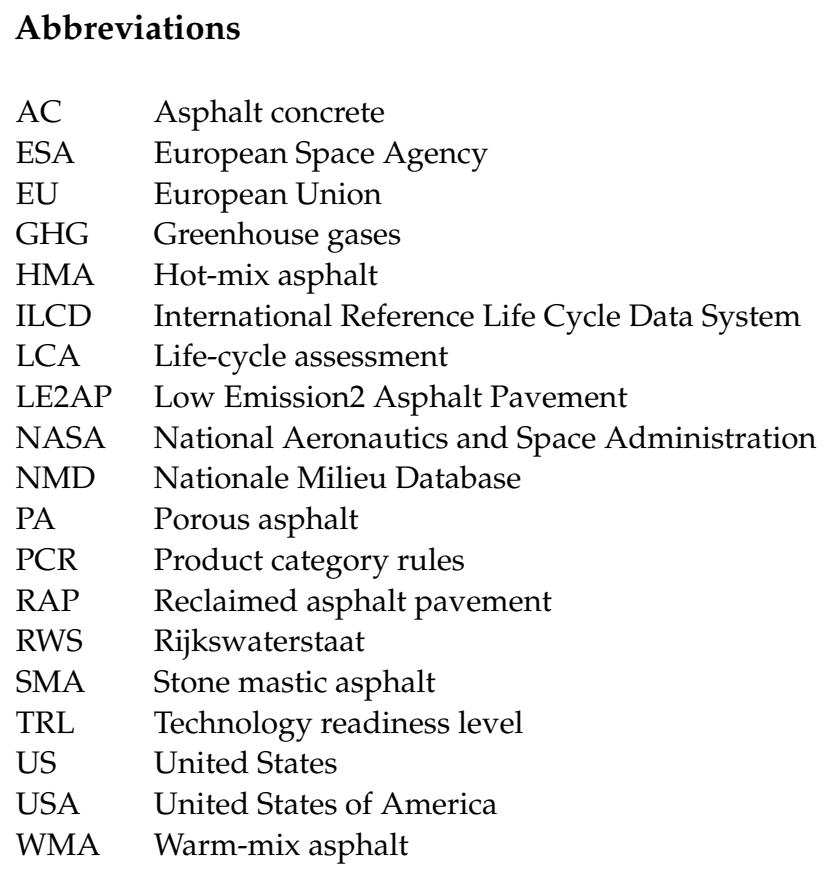

\section{References}

1. Sustain Euro Road About Sustain Euro Road. Available online: https://sustainableroads.eu/about-the-project/ (accessed on 22 December 2020).

2. Keijzer, E.E.; Leegwater, G.A.; de Vos-Effting, S.E.; de Wit, M.S. Carbon footprint comparison of innovative techniques in the construction and maintenance of road infrastructure in The Netherlands. Environ. Sci. Policy 2015, 54, 218-225. [CrossRef]

3. van IenW, M. CO - Managementplan Ministerie IenW 2018-2019; Ministerie van Infrastructuur en Waterstaat: The Hague, The Netherlands, 2018; p. 71.

4. Schwarz, A.; Overmars, L.; Godoi Bizarro, D.; Keijzer, E.; Kuling, L.; Van Horssen, A. LCA Achtergrondrapport voor brancherepresentatieve Nederlandse asfaltmengsels 2020. TNO Report R10987. 2020. Available online: https:/ /www.asfaltblij.nl/media/26 39/lca-achtergrondrapport-voor-nederlandse-asfaltmengsels-2020_v200928.pdf (accessed on 28 January 2021).

5. Santos, J.; Flintsch, G.; Ferreira, A. Environmental and economic assessment of pavement construction and management practices for enhancing pavement sustainability. Resour. Conserv. Recycl. 2017, 116, 15-31. [CrossRef]

6. Anthonissen, J.; Van den bergh, W.; Braet, J. Review and environmental impact assessment of green technologies for base courses in bituminous pavements. Environ. Impact Assess. Rev. 2016, 60, 139-147. [CrossRef]

7. Ozer, H.; Yang, R.; Al-Qadi, I.L. Quantifying sustainable strategies for the construction of highway pavements in Illinois. Transp. Res. Part D Transp. Environ. 2017, 51, 1-13. [CrossRef]

8. Giani, M.I.; Dotelli, G.; Brandini, N.; Zampori, L. Comparative life cycle assessment of asphalt pavements using reclaimed asphalt, warm mix technology and cold in-place recycling. Resour. Conserv. Recycl. 2015, 104, 224-238. [CrossRef]

9. Balaguera, A.; Carvajal, G.I.; Albertí, J.; Fullana-i-Palmer, P. Life cycle assessment of road construction alternative materials: A literature review. Resour. Conserv. Recycl. 2018, 132, 37-48. [CrossRef]

10. Zhao, Z.; Xiao, F.; Amirkhanian, S. Recent applications of waste solid materials in pavement engineering. Waste Manag. 2020, 108, 78-105. [CrossRef]

11. Vidal, R.; Moliner, E.; Martínez, G.; Rubio, M.C. Life cycle assessment of hot mix asphalt and zeolite-based warm mix asphalt with reclaimed asphalt pavement. Resour. Conserv. Recycl. 2013, 74, 101-114. [CrossRef]

12. Hasan, U.; Whyte, A.; Al Jassmi, H. Life cycle assessment of roadworks in United Arab Emirates: Recycled construction waste, reclaimed asphalt pavement, warm-mix asphalt and blast furnace slag use against traditional approach. J. Clean. Prod. 2020, 257, 120531.

13. Praticò, F.G.; Giunta, M.; Mistretta, M.; Gulotta, T.M. Energy and environmental life cycle assessment of sustainable pavement materials and technologies for urban roads. Sustainability 2020, 12, 704. [CrossRef]

14. Pantini, S.; Borghi, G.; Rigamonti, L. Towards resource-efficient management of asphalt waste in Lombardy region (Italy): Identification of effective strategies based on the LCA methodology. Waste Manag. 2018, 80, 423-434. [CrossRef] [PubMed]

15. Santos, J.; Bressi, S.; Cerezo, V.; Lo Presti, D.; Dauvergne, M. Life cycle assessment of low temperature asphalt mixtures for road pavement surfaces: A comparative analysis. Resour. Conserv. Recycl. 2018, 138, 283-297. [CrossRef]

16. Qiu, J.; Huurman, M.; de Bruin, B.; Demmink, E.W.; Frunt, M.H.T. Towards $90 \%$ warm re-use of porous asphalt using foaming technology. J. Clean. Prod. 2018, 190, 251-260. [CrossRef]

17. Vandewalle, D.; Antunes, V.; Neves, J.; Freire, A.C. Assessment of eco-friendly pavement construction and maintenance using multi-recycled rap mixtures. Recycling 2020, 5, 17. [CrossRef] 
18. Villares, M.; Işıldar, A.; van der Giesen, C.; Guinée, J. Does ex ante application enhance the usefulness of LCA? A case study on an emerging technology for metal recovery from e-waste. Int. J. Life Cycle Assess. 2017, 22, 1618-1633. [CrossRef]

19. van der Hulst, M.K.; Huijbregts, M.A.J.; van Loon, N.; Theelen, M.; Kootstra, L.; Bergesen, J.D.; Hauck, M. A systematic approach to assess the environmental impact of emerging technologies: A case study for the GHG footprint of CIGS solar photovoltaic laminate. J. Ind. Ecol. 2020, 24, 1234-1249. [CrossRef]

20. Piccinno, F.; Hischier, R.; Seeger, S.; Som, C. From laboratory to industrial scale: A scale-up framework for chemical processes in life cycle assessment studies. J. Clean. Prod. 2016, 135, 1085-1097. [CrossRef]

21. De Marco, I.; Iannone, R.; Miranda, S.; Riemma, S. An environmental study on starch aerogel for drug delivery applications: Effect of plant scale-up. Int. J. Life Cycle Assess. 2018, 23, 1228-1239. [CrossRef]

22. Lima, M.S.S.; Hajibabaei, M.; Hesarkazzazi, S.; Sitzenfrei, R.; Buttgereit, A.; Queiroz, C.; Tautschnig, A.; Gschösser, F. Environmental potentials of asphalt materials applied to urban roads: Case study of the city of Münster. Sustainability 2020, 12, 1-18.

23. Guerrieri, M.; Maini Lo Casto, B.; Peri, G.; Rizzo, G. Smart vs conventional motorways: Environmental impact assessment under realistic traffic conditions. Sci. Total Environ. 2020, 727, 138521. [CrossRef]

24. Chen, X.; Wang, H. Life cycle assessment of asphalt pavement recycling for greenhouse gas emission with temporal aspect. J. Clean. Prod. 2018, 187, 148-157. [CrossRef]

25. Arvidsson, R.; Tillman, A.M.; Sandén, B.A.; Janssen, M.; Nordelöf, A.; Kushnir, D.; Molander, S. Environmental assessment of emerging technologies: Recommendations for prospective LCA. J. Ind. Ecol. 2017, 22, 1286-1294. [CrossRef]

26. IPCC. Climate Change 2013: The Physical Science Basis. Contribution of Working Group I to the Fifth Assessment Report of the Intergovernmental Panel on Climate Change; Stocker, T.F., Qin, G.-K.D., Plattner, M., Tignor, S.K., Allen, J., Boschung, A., Nauels, Y., Xia, V., Bex, P.M.M., Eds.; Cambridge University Press: Cambridge, UK; New York, NY, USA, 2013; ISBN 978-92-9169-138-8.

27. Tissink, A. Tech Bedrijf Katerra Schiet de Bouwsector in één Keer een Nieuw Tijdperk inNo Title. Available online: https://www. cobouw.nl/bouwbreed/nieuws/2019/06/katerra-schiet-de-complete-bouwsector-eennieuw-tijdperk-in-101274171 (accessed on 22 December 2020).

28. European Commission. General Annexes to Horizon 2020 Work Programme 2014-2015; European Commission Decision C (2015)8621 of 4 December 2015; European Commission: Brussels, Belgium, 2015.

29. Read, J.; Whiteoak, D. The Shell Bitumen Handbook, 5th ed.; Thomas Telford Publishing: Cambridge, UK, 2003 ; ISBN 072773220 X.

30. Sarnowski, M.; Kowalski, K.J.; Król, J.B.; Radziszewski, P. Influence of overheating phenomenon on bitumen and asphalt mixture properties. Materials 2019, 12, 610. [CrossRef] [PubMed]

31. Jianying, Y.; Peiliang, C.; Shaopeng, W. Investigation of the properties of asphalt and its mixtures containing flame retardant modifier. Constr. Build. Mater. 2009, 23, 2277-2282. [CrossRef]

32. Williams, B.A.; Copeland, A.; Ross, C.T. Asphalt Pavement Industry Survey on Recycled Materials and Warm-Mix Asphalt Usage 2017 Information Series 138 8th Annual Survey; IS138 (8th edition); National Asphalt Pavement Association: Lanham, NE, USA, 2018. [CrossRef]

33. CROW. Deelhoofdstuk 31.2 Asfaltverhardingen-Actualisering; Ede: The Netherlands, 2010. Available online: https://docplayer.nl/ 12570911-Deelhoofdstuk-31-2-asfaltverhardingen.html (accessed on 28 January 2021).

34. Davidse, M.P.; Heesbeen, J.; de Looff, A.K.; Montauban, C.C. State of the Art Rapport Open Steenasfalt; Stichting Toegepast Onderzoek Waterbeheer: Amersfoort, The Netherlands, 2016.

35. RWS Infravation. Available online: https://rwsinnoveert.nl/@208051/infravation/ (accessed on 22 December 2020).

36. BAM Over LE2AP. Available online: https:/ / www.bamle2ap.nl/over-le2ap (accessed on 22 December 2020).

37. Kraton Corporation SYLVAROAD ${ }^{\mathrm{TM}} \mathrm{RP} 1000$ Performance Additive Brochure. Available online: https:// kraton.com/literature/ SYLVAROAD-RP1000-Performance-Additive-brochure.pdf (accessed on 22 December 2020).

38. De Vos-Effting, S.; Keijzer, E.; Jansen, B.; Zwamborn, A.; Mos, J.; Beentjes, T.; Jonkers, N.; Leendertse, P. LCA-Achtergrondrapport voor Nederlandse Asfaltmengsels. Rapport voor opname van brancherepresentatieve asfaltmengsels in de Nationale Milieudatabase. Versie 2.1. TNO 2017 R11029 (versie 2.1). 2018. Available online: https://www.asfaltblij.nl/media/2584/lcabrancherepresentatieve-asfaltmengsels-versie-21.pdf (accessed on 28 January 2021).

39. Waples, D.W.; Waples, J.S. A review and evaluation of specific heat capacities of rocks, minerals, and subsurface fluids. Part 1: Minerals and nonporous rocks. Nat. Resour. Res. 2004, 13, 97-122. [CrossRef]

40. Waples, D.W.; Waples, J.S. A review and evaluation of specific heat capacities of rocks, minerals, and subsurface fluids. Part 2: Fluids and porous rocks. Nat. Resour. Res. 2004, 13, 123-130. [CrossRef]

41. PBL. Klimaat-en Energieverkenning 2019; PBL: The Hague, The Netherlands, 2019.

42. Blankendaal, T.; Schuur, P.; Voordijk, H. Reducing the environmental impact of concrete and asphalt: A scenario approach. J. Clean. Prod. 2014, 66, 27-36. [CrossRef]

43. Tissink, A. BAM Peutert Zoab uit Elkaar tot Nieuwe Grondstoffen. Available online: https://www.cobouw.nl/infra/nieuws/20 15/10/bam-peutert-zoab-uit-elkaar-tot-nieuwe-grondstoffen-101129862 (accessed on 23 December 2020).

44. Platschorre, P. BAM legt Duurzaam Asfalt op Proefvak A73. Available online: https://www.cobouw.nl/infra/nieuws/2020/09/ bam-legt-duurzaam-asfalt-op-proefvak-a73-101287865 (accessed on 23 December 2020).

45. Farina, A.; Zanetti, M.C.; Santagata, E.; Blengini, G.A. Life cycle assessment applied to bituminous mixtures containing recycled materials: Crumb rubber and reclaimed asphalt pavement. Resour. Conserv. Recycl. 2017, 117, 204-212. [CrossRef] 
46. Almeida-Costa, A.; Benta, A. Economic and environmental impact study of warm mix asphalt compared to hot mix asphalt. J. Clean. Prod. 2016, 112, 2308-2317. [CrossRef]

47. Gevalideerde Producten. Available online: https://www.crow.nl/asfalt-impuls/projecten/asfaltkwaliteitsloket/gevalideerdeproducten (accessed on 21 January 2021).

48. Tissink, A. BAM Brengt Hogeschool Asfaltkunde in Praktijk Bij Grootschalige Vervanging Met 'Circulair' Zoab. Available online: https:/ / www.cobouw.nl/infra/nieuws/2019/05/hogeschool-asfaltkunde-vereist-bij-grootschalige-vervanging-metcirculair-zoab-101272788?_ga=2.74177242.939973248.1611233710-113873927.1611233710 (accessed on 21 January 2021).

49. Kim, D.; Norouzi, A.; Kass, S.; Liske, T.; Kim, Y.R. Mechanistic performance evaluation of pavement sections containing RAP and WMA additives in Manitoba. Constr. Build. Mater. 2017, 133, 39-50. [CrossRef]

50. Frigio, F.; Canestrari, F. Characterisation of warm recycled porous asphalt mixtures prepared with different WMA additives. Eur. J. Environ. Civ. Eng. 2018, 22, 82-98. [CrossRef]

51. Lu, D.X.; Saleh, M. Laboratory evaluation of warm mix asphalt incorporating high RAP proportion by using evotherm and sylvaroad additives. Constr. Build. Mater. 2016, 114, 580-587. [CrossRef] 